PART IV

Assessment of Self-Regulative
Traits 


\title{
18
}

\section{From Situation Assessment to Personality: Building a Social- Cognitive Model of a Person}

\author{
Vivian Zayas, Donna D. Whitsett, Jenna J.Y. Lee, Nicole \\ Wilson and Yuichi Shoda
}

\section{INTRODUCTION}

Cross-situational variability has posed a puzzle for personality psychology: How does one reconcile the fact that any given person's behavior varies across situations and from moment-to-moment with a central assumption of personality theories that personality is stable and consistent across situations? In other words, how does one account for the invariance of personality while at the same time taking into account the dynamic changes in the cognitions, affects, and behaviors experienced by the individual?

Take, for example, David Letterman. He has been a stand-up comic since 1975 and has been the host of one of the most watched late night shows in America. Each evening, he tells witty jokes, engages in playful banter with his audience, interviews his guests, and entertains millions of TV viewers with his trademark gap-toothed smile. It is therefore surprising to learn that in his personal life he is extremely shy and introverted
(Walters, 1992). How does one account for such variability?

In the last decade, research has shown that it is possible to identify predictable patterns of variability across situations. These patterns of cross-situational variability can be seen in stable if ... then ... situationbehavior profiles, or 'behavioral signatures' that characterize each individual (Shoda et al., 1994). They capture how a person's behavior varies reliably as a function of the particulars of the situation a person encounters. For example, David Letterman's behavioral signature could be described as: if David Letterman is performing on stage in front of thousands of people, then he is talkative, extraverted, and outgoing. If instead he is at a small, intimate gathering, then he is reclusive, withdrawn, and shy. But what about these situations is responsible for this pattern? Is it because the TV audience is anonymous and impersonal, or is it because there are well-defined scripts and props on the set, for example? 
In the present chapter, we propose that a key for understanding stable individual differences in people's behaviors, as well as the patterns of intraindividual variability for each person, is in knowing the features of situations that are psychologically active for a given person. Psychologically active features trigger particular cognitive and affective processes that ultimately lead to predictable responses in feelings, thoughts, and actions. This chapter will summarize and discuss recent conceptual and methodological advances in the identification of situational features. Three research examples illustrate six steps that can be used to identify (1) a set of psychological features that capture important aspects of a given situation, and (2) the features that are particularly salient for a given individual or groups of individuals. This approach, in turn, allows the assessment of each person's stable and distinctive 'behavioral signature', or if ... then ... situation-behavior profile, relating a person's thoughts, feelings, and behaviors to the situation, both external and internal, that the person encountered.

\section{MAKING SENSE OF CROSS- SITUATIONAL VARIABILITY: IF ... THEN ... SITUATION-BEHAVIOR PROFILES}

Some of the early evidence that cross-situational, intraindividual behavioral variability is meaningful (as opposed to error variance that needs to be removed or controlled) was obtained in a study of children at a residential summer camp (Shoda, 1990; Shoda et al., 1989, 1993a, 1993b, 1994; Wright and Mischel, 1987, 1988). Countless hours of observations revealed that each child's aggressive behaviors were systematically related to the features present in his or her situation. For example, for some children, being teased by peers elicited high levels of aggressive behavior, but being reprimanded by a counselor did not. Other children showed the opposite pattern; being scolded by a counselor elicited high levels of aggressive behaviors, but being teased by peers did not. Thus, each child was characterized by a unique 'behavioral signature', or if ... then ... situation-behavior profile (e.g., if teased by peers, then the child is aggressive.). Most importantly, these situation-behavior profiles proved to be highly stable across time. The child who showed the 'if teased by peers, then the child is aggressive' pattern during one half of the summer session showed a similar if ... then ... profile in the other half of the summer session.

\section{THE MIND AS A COGNITIVE-AFFECTIVE PROCESSING SYSTEM}

In response to the discovery of if ... then ... situation-behavior profiles, Mischel and Shoda (1995) proposed a reconceptualization of personality that could account for both the variability of a person's behavior across situations as well as consistency in a person's behavior over time. Inspired by cognitive and neural network models of the mind, the cognitive-affective processing system (CAPS) approach (Mischel and Shoda, 1995; Shoda and Mischel, 1998) conceptualizes each person's mind as a network of interconnected cognitions and affects. Figure 18.1 provides schematic representations of the CAPS networks of two hypothetical individuals.

A key premise of the CAPS approach is that each person's network remains unchanged from situation to situation. What changes from situation to situation are the particular cognitions and affects that become activated within the network, which in turn influence the corresponding behaviors that become expressed. Each person's unique and stable network is responsible for mediating the effect of the situation on behavior by guiding how a person encodes and construes a particular situation. The network also guides the goals, expectations, values, and strategies that become activated in the particular situation. The pattern and strength of 


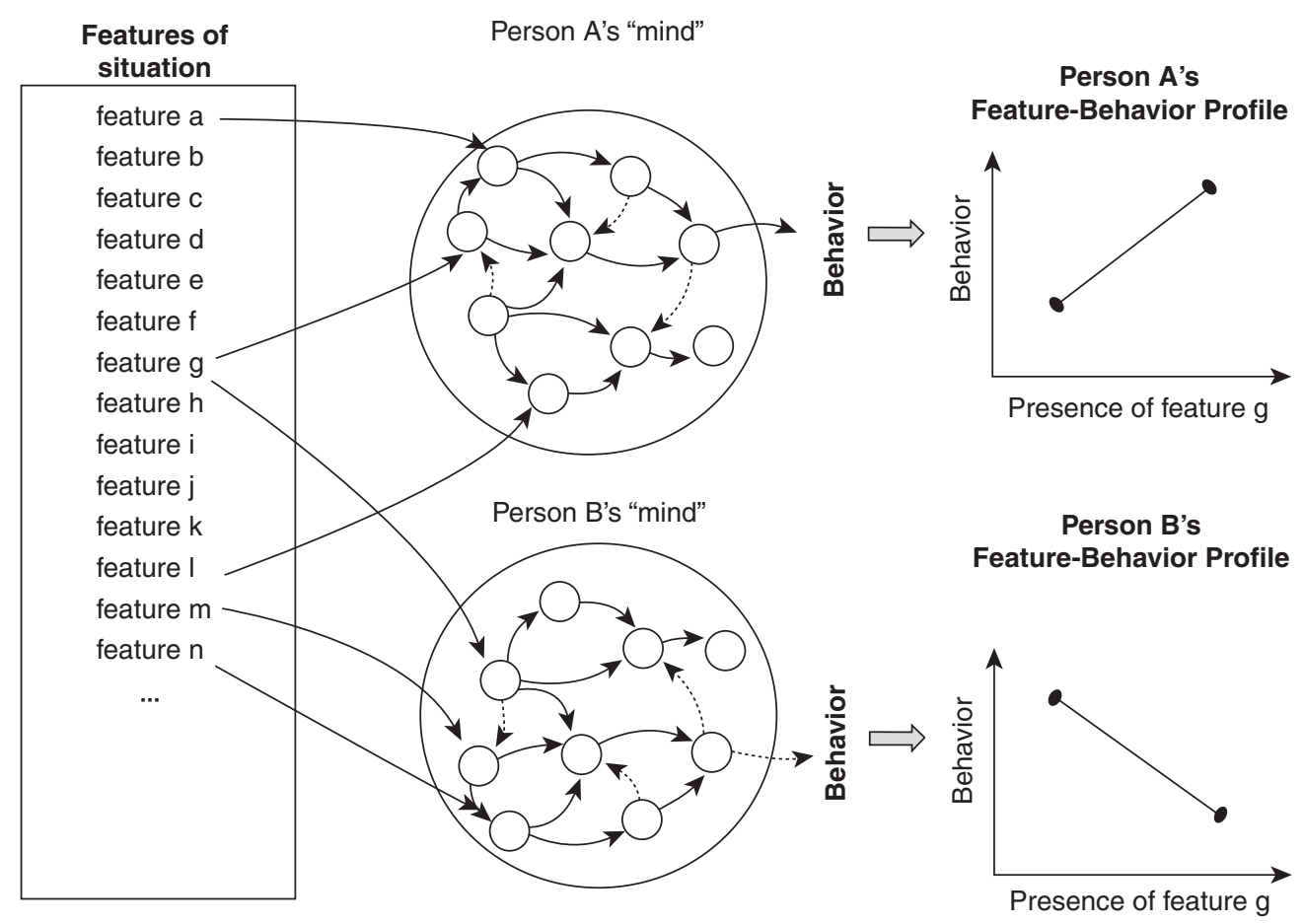

Figure 18.1 Schematic representation of the cognitive-affective processing system (CAPS) for two hypothetical individuals (i.e., person $A$ and person $B$ ). Each person's mind is conceptualized by a stable network of interconnected cognitions and affects that mediates the effect of the situational features on behavior. Solid lines within and outside of the network represent excitatory associations (e.g., activation of one cognition automatically activates associated cognitions). Dotted lines within and outside of the network represent inhibitory associations (e.g., activation of one cognition makes it more difficult to activate associated cognitions). In the above illustration, each person encounters the same situation that consists of a common set of features (e.g., a through $n$ ). Because not all features are meaningful for all people, Person $A$ and Person $B$ differ in the specific situational features that activate (or inhibit) certain cognitions and affects within each person's network, which in turn lead to a behavioral response.

associations among the cognitions and affects guide the activation of thoughts and feelings within the network. For example, when two cognitions are strongly associated with one another, the activation of one will automatically spread and activate the other. In contrast, when two cognitions are weakly associated or unassociated with one another, the activation of one will not necessarily activate the other. Associations among cognitions may also be inhibitory such that activation of one concept will make it more difficult to activate another.
The networks of the two individuals illustrated in Figure 18.1 are assumed to differ in the cognitions and affects that are available within each person's network, the strengths of associations among those available that influence the accessibility of particular cognitions and affects, and the strengths of associations between external features and cognitions and affects within the network.

The interactions among cognitive-affective processes within a person's network and the sensitivity of the network to situational, external or internal, influences give rise to 
observable, stable, and predictable patterns of if ... then ... situation-behavior profiles. For example, a situation may elicit an initial fear response in most individuals. For one individual the fear response may lead to increased attention and hypervigilance. For another individual, however, the fear response may lead to avoidance of the fear-eliciting stimulus. The first individual is characterized by an 'if afraid, then hypervigilance' pattern, whereas the second individual is characterized by an 'if afraid, then avoidance' pattern (Miller, 1987).

To summarize, at the surface level a person's behaviors may vary considerably from moment to moment and across a number of different situations, and may even appear disparate and inconsistent. Nonetheless, within this variability there may be stable and meaningful intraindividual patterns of consistency represented by if ... then ... situation-behavior profiles that uniquely characterize each individual. The ' $i f$ ' is the situation, either external (e.g., a request for public speaking) or internal (e.g., fear responses), and the 'then' is the affective, cognitive, and behavioral responses to the 'if'.

\section{PSYCHOLOGICALLY ACTIVE FEATURES OF SITUATIONS}

Because the nature of a person's network is revealed in observable if ... then ... situationbehavior profiles, predicting each person's behavior requires conceptualizing and assessing situations. What are the most important psychological features of a given situation? The first step is then to identify, for a given individual, those features that are 'psychologically active' and that trigger particular cognitive-affective processes within a person's network and lead to behavioral responses.

How does one conceptualize and assess a situation, particularly the psychologically important features of a situation? Initial efforts at classifying situations were based on nominal features, such as whether a behavior occurred in a playground or cafeteria
(Hartshorne and May, 1928; Newcomb, 1929). A limitation of this approach is that it is unclear how to generalize the results to other situations. For example, if a child behaves aggressively at the playground, but is friendly and agreeable in the cafeteria, what would one predict her behavior to be in a classroom? When situations are defined nominally, knowledge of past behavior (e.g., aggressive at the playground) is useful in predicting behavior only in that exact situation, but shows little generalizability to other situations (e.g., aggressive when working on homework with peers; Hartshorne and May, 1928).

Going beyond this limitation requires understanding, for a given person, the most influential psychological features of the situation. What feature or features of the situation most strongly affect that individual's behavior? For example, imagine one knows that the reason why the child is aggressive at the playground is because she becomes insecure when she feels that she is being excluded by her classmates. Then one may predict that even in a cafeteria, which shows little physical resemblance to the playground, she will become aggressive if her peers start talking about their weekend plans to spend time together but do not invite her.

Social psychology has uncovered situational determinants of various behaviors (e.g., aggression, conformity, affiliation) and often focuses on the most important psychological features of situations, such as the effects of power, fear, authority, and group pressure. Despite the vast research on situational influences on social behavior, a systematic effort to develop a taxonomy of situations has only begun (Kelley et al., 2003). Furthermore, it is quite possible that a 'one-size-fits-all' taxonomy may not be adequate. That is, the features of psychological situations serving as the 'ifs' in individuals' characteristic if ... then situationbehavior profiles may depend on the particular individual as well as the particular situation and behavior in question. For example, for the child who becomes aggressive when she feels excluded by her peers, the feature of the situation involves interpersonal rejection, 
perceived or actual, by her peers. This feature, however, may be of lesser or no importance to another child who instead becomes aggressive and belligerent when teachers give him poor marks on assignments. For the first child, the psychologically active feature is peer rejection. For the second child, it is negative evaluations from an authority figure.

\section{METHODS FOR IDENTIFYING PSYCHOLOGICAL FEATURES OF SITUATIONS}

Consider the myriad ways in which a situation can be conceptualized and operationalized. Is it even possible to find a small enough number of features that can provide a reasonably comprehensive description of the situations, which in turn can be used to characterize if ... then ... situation-behavior profiles? Ultimately, this is an empirical question. However, following the success in identifying the psychological features of situations influencing children's behaviors in the summer camp, methods for assessing if ... then ... profiles in a number of different domains have been developed.

Three examples of research programs aimed at identifying psychological features of situations are presented below. In a departure from techniques used in the original summer camp study (e.g., Shoda et al., 1994), the three illustrations introduce a new approach for assessing feature-behavior profiles. Instead of classifying 'ifs' on discrete categories (e.g., peer teasing vs. teacher praise), the latest techniques attempt to assess on continuous scales the degree to which each psychological feature was present in a given situation. As will be described, the use of continuous indices of situational features allows the use of multi-level analysis to simultaneously estimate (i) the expected effect of a feature on the average individual's behavioral response (conceptually similar to the main effect of the feature), (ii) the effect of the feature on a given individual's behavioral response, and (iii) interindividual differences in behavioral responses to the feature.
One goal of such research is to determine a common set of features influencing a particular response. For example, as illustrated in Figure 18.1, a situation may consist of features $a, b, c, d, e$, and so on. In addition, this type of research aims to identify those features that are particularly salient for a given individual or groups of individuals. Such features are considered 'psychologically active features' or 'psychologically active ingredients' of situations. For example, as illustrated in Figure 18.1, person $A$ 's behavior may be highly influenced by features $a, g$, and $l$. Person $B$ 's behavior may be highly influenced by features $g, m$, and $n$. And yet another person's behavior may not be affected by any of the features. Thus, the process of feature identification - both to obtain a common set of features as well as to identify those features that are 'psychologically active' to a particular individual or group of individuals - is akin to identifying a set of environmental allergens to which some individuals have a strong reaction, while other individuals do not.

Often, the presence of psychologically active features triggers particular cognitiveaffective processing dynamics within a person's network that leads to an increase in the expression of a particular behavior. For example, someone who enjoys novel experiences may express greater positive affect in response to novelty-related features. Such $\mathrm{fea}$ ture-behavior links are excitatory. However, psychologically active features can also activate cognitive-affective processing dynamics that may lead to a decrease in the behavior of interest. Such feature-behavior profiles may be considered inhibitory in nature. For example, in the classic bystander intervention studies (e.g., Darley and Latané, 1973), the number of other people present in a situation can be considered an important active feature of the situation for some individuals in that the feature suppresses the helping behavior that they may have otherwise engaged in. As will be discussed in the 'Further Considerations' section, the relation between the presence of a feature and resulting response may not necessarily reflect a one-to-one correspondence. 
Rather, it may be influenced by the occurrence of other features also present in the situation. However, as a first step in feature identification and its effect on subsequent responses, this chapter will focus on the identification of features that have been shown to singularly influence behaviors.

To determine the psychological features of a situation - both the set of features that captures the most important psychologically meaningful aspects of situations as well as those features that are psychologically active for a given individual or group of individuals one method is to use a top-down approach, basing identification of features on preexisting theory and research. This entails culling the literature for features of situations that are likely to influence the behavior of interest and developing stimuli that differ on the features selected. For example, if one were interested in the features of situations influencing partner preference, one might turn to past research that has identified the characteristics of potential dating partners (e.g., physical appearance, similarity to self) influencing perceived attractiveness. Another method for identifying features of situations involves using a bottom-up approach. In this approach, people's responses to a number of situations are recorded. One then asks: which situations elicit similar responses among different people and what do these situations have in common? Finally, a combination of the two approaches may at times be used.

The following sections provide step-by-step illustrations of three approaches for identifying psychological features of situations. Although the three approaches differ procedurally, they all employ the following six steps to identify psychological features of situations:

1 One needs to identify the domain of situations in which the behavior of interest occurs (Shoda et al., 1994).

2 The researcher then needs to develop (e.g., by conducting a separate study) or obtain, if possible, (e.g., from prior research) a relatively large number of stimuli that represent the situations of interest.

3 The next step is to identify a common set of psychological features that capture the most important aspects of the situations and that are likely to influence the behavior of interest.

4 Objective indices reflecting the extent to which each of the features is present in the stimuli are derived.

5 In a sample of individuals whose behavioral signatures the researcher is seeking to understand, a highly repeated within-subjects research design (Shoda, 2003) is used to observe and record participants' behavioral responses across the different situations.

6 Through the use of multi-level analyses, it is then possible to determine the effect of individual features and interactions among features, on a given individual's responses as well as to identify 'psychologically active features' for a given individual or group of individuals.

\section{Top-down approach to identifying psychological features of situations influencing partner preference}

For some research questions, it may be useful to turn to past research and theory to identify candidate features of situations that are likely to influence a given behavior. For example, research and theory in social psychology has extensively examined the situational factors influencing person perception, attribution, impression formation, and spontaneous inference, to name just a few. This body of knowledge is a good starting point in identifying a common set of psychological features. Similarly, research on response to failure and experience of threat, as well as work on stereotypes, is also likely to inform the initial feature identification process. Ultimately, these possible features need to be empirically validated using methods such as those described in this chapter.

An illustration of a top-down approach is given in a study by Zayas and Shoda (2007), who set out to examine the question: Are women who have been the victim of psychological abuse in the past more likely to prefer an abusive dating partner in the future? This question was motivated by the widespread belief among lay persons, academics, and professionals alike that some people may be recreating negative 
relationship experiences through the dating partners they select, or attract. In a departure from traditional conceptualizations of situations, the researchers defined situations as another person (i.e., a potential dating partner). In this context, psychological features can be conceptualized as the personality characteristics of the potential dating partners (Zayas et al., 2002). In the present example, the features were identified a priori using existing research on the characteristics associated with victimized women and abusive men. Zayas and Shoda then tested the hypothesis that personality characteristics associated with abusive individuals (e.g., possessiveness and aggressive behaviors) in male potential partners may be the 'active psychological ingredients' that attract some women and repel others. The following section discusses the Zayas and Shoda (2007) study as a way of providing a step-by-step illustration of a theory-driven top-down approach for identifying psychological features.

Step 1: Identify the situations in which the behavior of interest is likely to take place

As a first step in identifying the psychological features of situations, the researcher must identify the situations in which the behavior of interest is likely to take place. In the present research illustration, the behavior of interest was college-aged women's preferences for male college-aged dating partners who may be potentially psychologically abusive. Thus, in this context, situations were operationalized as descriptions of potential dating partners in the form of personal ads. Features of the situations were the characteristics of the dating partners conveyed in the personal ads that were hypothesized to influence behaviors (i.e., preferences). Ideally, in this initial step, the researcher aims to identify the universe of situations in which the behavior of interest is likely to occur. Given the difficulty of this task, the researcher may choose to refine and narrow his or her definition of the behavior of interest. For example, in the present example the researchers focused on preferences for college-aged dating partners, rather than dating partners of all ages or non-college students.

\section{Step 2: Gather specific stimuli representing the situations of interest}

To develop stimuli for the study, 112 male college students wrote short descriptions of themselves in the form of personal ads. Because the researchers were specifically interested in whether characteristics associated with an abusive personality were psychological features of situations influencing women's preferences in potential partners, it was necessary to assess whether the stimuli generated (i.e., 112 personal ads) possessed these characteristics. Three female undergraduate research assistants, who were unaware of the research hypotheses, provided initial evaluations of all 112 personal ads with regard to the degree to which the men described in the ads would be perceived by women, on average, as being (1) potentially abusive, and (2) desirable as a dating partner. Coders' evaluations, however, indicated that none of the ads were perceived as both potentially abusive and highly desirable, and that only 4 of the 112 ads were consensually evaluated as potentially abusive. Because it was not feasible to have participants in a study read all 112 ads, the following three types of dating partners were selected for the study: (1) four ads that described potential dating partners that were rated high on abusiveness and low on desirability (abusive); (2) eight ads that described potential dating partners that were rated low on abusiveness and low on desirability (undesirable); and (3) four ads that described potential dating partners that were rated low on abusiveness and high on desirability (desirable).

\section{Step 3: Identify a common set of features that could be used to capture the most psychologically important aspects of the situation of interest}

The next step is to identify features of the situation of interest. Past research and theory were used to identify the relevant 
features a priori. In particular, past research has linked characteristics such as jealousy, impulsivity, dependence, and violence with an abusive personality in men (e.g., Dutton et al., 1996; Dutton and Browning, 1988; Murphy et al., 1994; Walker, 1979). Thus, a top-down approach involves validating the extent to which the a priori features were present in the stimuli.

\section{Step 4: Code the stimulus set according to a list of relevant features and derive indices reflecting presence of features}

Construct validation and continuous indices of the features were obtained by having separate samples of female college students evaluate the descriptions. Specifically, some women $(n=24)$ rated the extent to which they perceived the man described in each of the 16 personal ads to be potentially abusive, psychologically and physically, with a romantic partner. A different sample of female college students $(n=22)$ rated the extent to which the man described in each ad was a desirable dating partner and someone they would be interested in dating. (These two ratings were averaged within each rater to index the desirability associated with each male dating partner.) In addition, both samples of female raters indicated the extent to which each male dating partner possessed personality characteristics that past research has linked to an abusive personality in men, including jealousy, impulsivity, dependence, and violence.

To create continuous indices that characterized each of the 16 male dating partners in terms of the psychological features (e.g., potential for abusiveness, aggressiveness, desirability, impulsivity, possessiveness), all the ratings were averaged across raters. Cronbach's alpha estimate $(\alpha)$ of the reliability of the index was computed to estimate the reliability of each index. Cronbach's alphas were 0.93 and 0.89 for the potential for abusiveness and desirability indices, respectively, and ranged from 0.72 to 0.87 for the specific personality characteristics (e.g., aggressiveness, jealousy, impulsiveness).
Not only did the women's ratings provide a continuous measure of the features present in each ad, they also provided support for the initial classification of the ads. Specifically, the abusive dating partners were rated as significantly more likely to inflict psychological as well as physical abuse than the undesirable and desirable dating partners. The desirable dating partners were rated as significantly more desirable than the undesirable and abusive men, which were rated as approximately equally undesirable. Adding further validity to the ads used as stimuli, abusive dating partners were rated as more impulsive, jealous, possessive, dependent, clingy, aggressive, hostile, violent, and angry than the undesirable and desirable dating partners. Undesirable and desirable ads did not differ from each other on any of these characteristics. As an additional step in the construct validation of the 16 personal ads, the relation between female raters' judgments of the ads and the male ad writers' own self-reported characteristics was examined. Correlations between men's self-reports and the female raters' judgments of the ads showed moderate to high convergence. Specifically, women's ratings of each ad writer's potential for psychological abuse were positively correlated in the expected direction with ad writer's selfreported hostility, impulsivity, jealousy, and past experiences behaving in psychologically abusive ways (e.g., controlling, jealous, verbally abusive).

\section{Step 5: Use a highly repeated within- subjects design to observe and record responses to stimuli}

In this study, the research employed a highly repeated, multi-level approach (Shoda, 2003) in which a person's preference was assessed across 16 potential dating partners, who varied systematically on key personal characteristics or 'psychological ingredients' (Zayas et al., 2002). Given that the behavior of interest was preferences for dating partners, the situations involved providing individuals with the opportunity to express their preferences. Therefore, the study procedures 
employed an Internet dating service paradigm in which participants read about the different potential dating partners and indicated through a four-round selection process who they wanted to get to know better.

\section{Step 6: Analyze each participant's responses as a function of the situation}

The focus on the analysis of psychological features of situations, and identifying individuals' behavioral signatures with regard to such features, calls for a shift in the general paradigms used for social and personality psychology research. Specifically, the traditional 'one-shot' data collection approach, which examines individual differences at one time in one situation, has intrinsic limitations for discovering patterns of psychological regularities within each person. An alternative approach, which might be called a 'highly repeated, within-subjects design' (Shoda, 2003) allows a systematic and quantitative characterization of if ... then ... situation-behavior profiles, for each person, by within-subject regression analyses. These individual-level characterizations can in turn be predicted from individual difference variables, using a multi-level modeling approach (e.g., HLM, hierarchical linear modeling). The set of level-1 coefficients from such analyses, describes the effect of each situation feature within a given individual. Thus, it is a behavioral signature, specifically, a feature-behavior profile, that can be computed with continuous, rather than categorical, characterization of situations with regard to the degree to which each psychological feature is present.

To illustrate, Zayas and Shoda (2007) used multi-level modeling to predict, for each woman, the effects of psychological features on partner preference. ${ }^{1}$ Specifically, as shown in equation (18.1), the level-1 model examined, for each woman, the relation between the presence of particular features (e.g., aggressiveness and desirability) that characterized each potential dating partner and the behavior of interest (i.e., preference for each dating partner). ${ }^{2}$ The level-1 model is as follows:

[Preference for partner $i]_{i}$

$=b_{\text {aggressiveness } j}$ [partner $i$ 's aggressiveness]

$+b_{\text {desirability } j}$ [partner $i$ 's desirability] $+r_{i j}$

Because each woman can now be characterized by a $b_{\text {aggressiveness } j}$ and $b_{\text {desirability } j \text {, these }}$ coefficients can be used to represent her feature-behavior profile. For example, Table 18.1 reports the level-1 regression equations for five participants. As shown, for participant 308 there is an inverse relation between the aggressiveness of the potential dating partner and her preference for the dating partner $\left(b_{\text {aggressiveness } j}=-0.80\right)$; she was less likely to prefer a potential dating partner who was perceived by other women to be aggressive. This woman also shows a slight positive relation between the desirability of the dating partner and her preference $\left(b_{\text {desirability } j}=\right.$ 0.13 ), such that the more desirable the

Table 18.1 Level-1 regression equations predicting for each participant the effect of partner aggressiveness and desirability on her partner preference

\begin{tabular}{lll}
\hline Participant & $P M I$ & Level-1 regression equation \\
\hline 308 & 0.02 & [Preference for partner $i]_{j}=-0.80\left[\right.$ partner $i$ 's aggressiveness] +0.13 [Partner $i$ 's desirability] $+r_{i j}$ \\
241 & 0.05 & [Preference for partner $i]_{j}=-0.04\left[\right.$ partner $i$ 's aggressiveness] $+1.38\left[\right.$ partner $i$ 's desirability] $+r_{i j}$ \\
293 & 0.08 & [Preference for partner $i]_{j}=-0.53$ [partner $i$ 's aggressiveness] $+-0.02\left[\right.$ partner $i$ 's desirability] $+r_{i j}$ \\
287 & 2.13 & [Preference for partner $i]_{j}=0.41$ [partner $i$ 's aggressiveness] $+0.61\left[\right.$ partner $i$ i's desirability] $+r_{i j}$ \\
289 & 2.24 & [Preference for partner $i]_{j}=0.89\left[\right.$ partner $i$ 's aggressiveness] + 1.58[partner $i$ 's desirability] $+r_{i j}$ \\
\hline Notes: Each participant's regression equation predicts her preferences for each dating partner as a function of the dating \\
partner's aggressiveness and desirability. Each woman's score on the self-report measure assessing frequency of experienc- \\
ing psychological abuse in her most recent romantic relationship is reported in the second column (range of possible scores \\
$=0-4)$. PMI = Psychological Maltreatment Inventory.
\end{tabular}


partner, the more likely she was to select him. Visually scanning the coefficients for the different women in the study, one sees that the pattern differs for each one. For participant 287, aggressiveness is positively related to her partner preference $\left(b_{\text {aggressiveness } j}=0.41\right)$ and so is desirability $\left(b_{\text {desirability } j}=0.61\right)$. It is important to keep in mind that features that do not appear to have an effect on responses, as indexed by regression coefficients that are not statistically different from zero, may still be psychologically meaningful, but may not lead to observable responses.

Are the differences in women's profiles, as represented by the level-1 regression coefficients meaningful? To the extent that the answer is yes, one would expect that these coefficients could be predicted by individual difference measures. For example, do women who have experienced more instances of psychological abuse show a preference for potentially abusive dating partners? To identify the features of situations that may be particularly salient (i.e., 'active') for women with a higher incidence of experiencing psychological abuse in a past romantic relationship, the set of level-1 coefficients can, in turn, be predicted by individual difference variables, such as a woman's past relationship experiences. Specifically, the level-2 model is a between-subjects analysis that predicts each woman's preference for potentially abusive dating partners, as reflected in $b_{\text {aggressiveness } j}$, from the degree to which she had experienced psychologically abusive behaviors in her past romantic relationship as assessed by the Psychological Maltreatment Inventory (PMI; Kasian and Painter, 1992). The level-2 model is as follows:

\section{$b_{\text {aggressiveness } j}=\gamma_{\text {aggressiveness } 0}+\gamma_{\text {aggressiveness } 1}$ [participant $j$ 's past experiences of psychological abuse $]+\mu_{\text {aggressiveness } j}$}

\footnotetext{
$b_{\text {desirability } j}=\gamma_{\text {desirability } 0}+\gamma_{\text {desirability } 1}$ [participant $j$ 's past experiences of psychological abuse $]+\mu_{\text {desirability } j}$
}

In these equations, the level-2 intercepts, $\gamma_{\text {desirability } 0}$ and $\gamma_{\text {aggressiveness } 0}$, can be interpreted as the expected average effect of partners' desirability and potential for aggressiveness, respectively, on partner preference, from a participant who was average on the level-2 predictor (because all level-2 variables were centered, level-2 intercepts predict the level1 coefficients for participants at the mean of the distribution).

The results of the Zayas and Shoda study showed that the frequency with which women reported experiencing psychologically abusive relationships in their past was positively related to preferences for aggressive dating partners, even though the effect of desirability was statistically controlled in the level-1 model $\left(\gamma_{\text {aggressiveness } 1}=0.28, p<\right.$ 0.001). In addition, when the HLM analysis was repeated in order to examine the effect of different features on preference, the results showed that women who reported more psychological victimization in their most recent romantic relationship showed a stronger preference for dating partners who had been judged to be impulsive, jealous, possessive, hostile, and violent. All of these characteristics have been linked to personality characteristics of abusive men (e.g., Dutton et al., 1996). Thus, these characteristics are the features of situations or 'psychological ingredients' that differentially affected women's partner preferences.

In addition to identifying features of situations that have high functional significance for a given person, the analysis also allowed one to see how a person's partner preference varies as a function of a common set of 'psychological ingredients' present in the situation. For this analysis, situations were classified into 'abusive', 'undesirable', and 'desirable', allowing each woman's 'behavioral signature' to be assessed using the more categorical approach to situation assessment used in earlier work (Shoda et al., 1994). For example, as shown in Figure 18.2, the 'behavioral signature' for women who had experienced psychological abuse differed meaningfully from the 


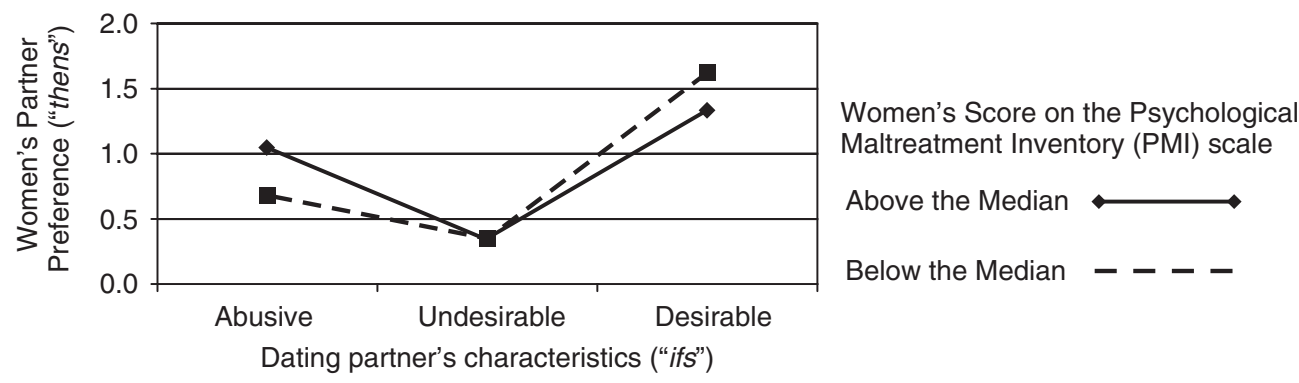

Figure 18.2 The characteristics of the potential dating partners (i.e., desirability and potential for abusiveness) are the 'psychological ingredients' of the situation, and partner preference ('thens') varied systematically as a function of the dating partner's characteristics ('ifs'). Women who had been the victim of psychological abuse (i.e., scoring above the median on the PMI) showed if ... then ... (situation-behavior) profiles that were distinct from the profiles that characterized women who had experienced less abuse (i.e., scoring below the median on the PMI). Figure is reproduced from Zayas and Shoda (2007).

if ... then ... 'behavioral signature' for women who had not.

\section{BOTTOM-UP APPROACH TO IDENTIFYING PSYCHOLOGICAL FEATURES OF SOCIAL SUPPORT SITUATIONS}

Given that the endeavor of identifying features of situations is relatively new, even in well-developed research areas, it is possible that not all the relevant psychological features affecting individual differences in behavior have been identified. Thus, for some research questions, it may be useful to utilize bottom-up approaches in which identifying the psychologically active features of situations is based on responses provided from individual participants rather than from existing theory and research.

The research below illustrates a bottom-up approach to answer the question: What are the features of situations that influence whether one person perceives that another needs help, specifically social support? Certainly, it is not simply a matter of hearing the person say 'I need help', because distressed individuals may have good reason to not express an explicit desire for help.
A direct request for help involves the possibility of rejection or stigmatization, can be associated with feelings of loss of independence, and comes with the knowledge that one could be burdening the listener (Goldsmith and Parks, 1990). If people in distress do not directly ask for support, what situational features do potential support providers (PSPs) rely on to determine whether someone needs help? Is a person who clearly and freely expresses nonverbal signals of distress (e.g., a large variety and high frequency of negative facial expressions) more likely to be perceived as needing help compared to someone who attempts to manage their distress (e.g., attempting to suppress the expression of negative emotions)? The research described below examined the support seeker's verbal and nonverbal communication as possible key ingredients of the situations that PSPs encounter.

\section{Step 1: Identify the situations in which the behavior of interest is likely to take place}

The present research example focuses on situations in which one person is distressed and another person has the opportunity to provide support. Distress signals may differ depending on the nature of the distresseliciting event and context in which they occur. 
For example, it may be perceived as more acceptable to freely express sadness and grief in response to a family member's death, but less so in response to a loss at an athletic event or competition. As a first effort in understanding the features of situations that are 'active' and addressing the question, 'What features of situations do PSPs rely on to determine whether someone needs help?', the researchers deliberately limited their focus to situations in which individuals believed that they would have to engage in an aversive behavior (i.e., eating dried worms). By equating the nature of the distressing situation encountered, the range of psychological features that could play a role in determining potential support providers' responses (e.g., perceptions that a discloser needs help) was restricted. Constraining the range of psychological features affects the generalizability to other kinds of distressing situations. Nonetheless, it is a first step in determining the effectiveness and feasibility of such an approach.

\section{Step 2: Gather specific stimuli representing} the situations of interest

The next step is to identify a set of stimuli that capture the most psychologically important aspects of the situation of interest. For this purpose, a sample of situations was developed by asking 65 different people to serve as disclosers. Upon arriving in the laboratory, the disclosers were led to believe they were in a taste-testing study in which they would be eating dried worms. Past research has shown that individuals react negatively in response to this procedure (Johnson, 2006). Prior to performing the presumed dried worm taste-test, a video recording was made of each of these 65 disclosers while they were interviewed, 'so that future participants would know what the study was like.' Disclosers were asked to describe their experience, say how they felt about it (positive, negative, or neutral) and to elaborate on their response. Each interview lasted approximately five minutes.

Videotaped interviews were edited in order to delete the interviewer's questions and focus solely on disclosers' responses. Any responses not having to do with the discloser's response to the worms (e.g., disclosers' descriptions of the study procedures) were also deleted. The final clips were between 20 and 25 seconds in length. Therefore, after completing this step in the process, there were 65 clips that could be presented to a new group of participants.

\section{Step 3: Identify a common set of features that could be used to capture the most psychologically important aspects of the situation of interest}

All the video clips developed from the first study were then presented to a different sample (from the same population of interest) to identify the psychological features of the situation; namely, the features of situations to which people respond when deciding whether or not another person needs help (Whitsett and Shoda, 2007). Participants $(N=58)$ viewed randomly assigned pairs of clips, with each video depicting a different person describing his or her response to the distressing event. ${ }^{3}$ Participants selected one clip from each pair in terms of who they thought needed more help, which was defined to participants in the following way: "By "needs help" we mean that the person would benefit from someone providing some comforting words of support. An example of this type of help is someone saying, "I know how you feel" to the person'. To identify the features that affected their judgment of who needed more help, they were asked to reply to an open-ended question asking why they chose one individual over the other. Participants were asked to type a few sentences explaining their choice for each pair. In a variation of this method, participants could be asked to rate the extent to which each person needed help instead of making a choice between two disclosers, and then explain why they gave each person the rating they did.

The result of this step was a large qualitative dataset, which consisted of reasons participants spontaneously provided for 
perceiving one discloser as needing more help compared to another discloser (32 video pairs $\times 58$ participants $=1,856$ responses). Several steps were taken to extract the important psychologically meaningful features from these data, which entailed creating a bottom-up coding system (Lampert and Ervin-Tripp, 1993). First, two coders read through all responses, noting any features that were consistently mentioned by a number of participants. Features were quite diverse, including demographics (e.g., gender), personality characteristics (e.g., shyness), and specific behaviors (e.g., fidgeting). A list of 99 themes was developed, providing a preliminary list of psychological features.

The open-ended responses were then read through a second time, with the goal of coding every response using the preliminary list of 99 features. In cases when coders encountered a response that could not be coded using the preliminary list of features, a new code was added. As a result, there were 120 features in the preliminary list. Next, each rater coded $60 \%$ of the responses and determined how frequently each of the 120 features was mentioned in each participant's response. Because there was a $20 \%$ overlap between coders, it was possible to compute inter-rater reliabilities, using Cronbach's alpha, for each feature. To reduce the list of 120 features, only the 30 of the 120 features that were reported by at least $10 \%$ of participants and had a Cronbach's alpha of greater than 0.70 were retained. These features are listed in Table 18.2. Given that participants' responses were obtained in open-ended format questions, $10 \%$ of participants spontaneously reporting the same feature is considerable. ${ }^{4}$ To summarize, the coding procedure reduced the preliminary list of 120 features to a more manageable list of 30 features.

\section{Step 4: Code the stimulus set according to a list of relevant features and derive indices reflecting presence of features}

After establishing a list of features relevant for the situations, the next step was to rate each video, on a 7-point Likert scale, according to the degree to which each feature was present in the clips. A new group of individuals, similar in characteristics to those participating in the final study of interest, rated the videos with regard to the list of features. In this way, the presence of psychological features of situations in the set of stimuli is rated from the perspective of the individuals who are similar to the eventual test participants. In addition, given that these judgments will be used to develop a consensually agreed-upon index to capture the extent to which each feature is present in a situation, the greater the number

Table 18.2 List of 30 features identified as describing the most psychologically important aspects of one type of distressing situation

\begin{tabular}{|c|c|c|c|}
\hline 1. & Negative expectations about what is to come next & 16. & Tense body \\
\hline 2. & Disgust & 17. & Nervous tics (playing with earlobe, hair, etc.) \\
\hline 3. & Lack of confidence & 18. & Looks at worms \\
\hline 4. & Distressed/upset & 19. & Looks down \\
\hline 5. & Angry & 20. & Voice in general indicates a negative state \\
\hline 6. & Scared & 21. & Quiet voice \\
\hline 7. & Anxious & 22. & Words that are used indicate a negative state \\
\hline 8. & Surprised & 23. & Relays a negative personal memory \\
\hline 9. & Negative attitude & 24. & Focuses on negative aspects of the task \\
\hline 10. & 'Playing it cool'/covering up true feelings & 25. & Is willing to try the worms/open-minded \\
\hline 11. & Convincing self & 26. & Task seems difficult for the discloser \\
\hline & Conveys a forced/ fake smile & 27. & Willing to try the worms, but with reservations \\
\hline 13. & Conveys nervous laughter & 28. & Not open to experience/opposed to trying worms \\
\hline 14. & Body movements in general indicate a negative state & 29. & Has no previous experience with worms \\
\hline 15. & Engages in fidgeting/squirming & 30. & Participant can relate to person/understand point-of-view \\
\hline
\end{tabular}


of raters, the more reliable the index becomes.

In order to make the task more manageable for raters, each rater was responsible for only one feature. Ten raters were assigned to each feature, and their responses were averaged for each video clip. By having multiple raters per feature, idiosyncratic responses cancel each other out when averaged with the responses of other raters. After averaging across raters, each video has a value assigned to it for each feature, indicating the level of each feature contained in each of the 65 video clips. The reliability of these indices can be computed using inter-rater correlations, Cronbach's alpha, or both.

\section{Step 5: Use a highly repeated within- subjects design to observe and record responses to stimuli}

Now that the important features and the level of presence in each of the videos are known, it is possible to examine how responses to the clips are based on features contained in the clips. A new group of participants served as the PSPs and were asked to view the videos and respond, for each one, with how much help (on a Likert scale) they think each person needs.

\section{Step 6: Analyze each participant's responses as a function of the features of the situation}

For each individual PSP, his or her perception of disclosers' need for help can be predicted as a function of the various features of the film clips. Specifically, multi-level modeling can be used to predict, for each potential support provider, the effects of psychological features on perceived need for help. As shown in equation (18.4), the level1 model predicts, for each PSP, the extent to which disclosers' negative expectations and expressions of disgust influence his or her perception that a discloser needs help. The level-1 model is as follows:

$$
\begin{aligned}
& \text { [Perceived need for help } i]_{j} \\
& \quad=b_{0}+b_{\text {neg.expectations } j}[\text { discloser } i \text { 's } \\
& \quad \text { negative expectations }]+b_{\text {disgust } j} \\
& \quad \text { [discloser } i \text { 's disgust }]+r_{i j}
\end{aligned}
$$

Table 18.3 reports the regression equations for five participants. As shown, for PSP 1, the more negative expectations and disgust that a discloser displays, the more likely she is to perceive that the discloser needs help. The feature-behavior profile for PSP 2 is somewhat different. As for PSP 1, the more a discloser displays negative expectations, the more PSP 2 is likely to help. However, unlike PSP 1, disgust does not appear to be a relevant feature for PSP 2.

It can also be determined if there are systematic differences between PSPs in what features of the disclosers' expressions of distress prompt the perception that help is needed. Recall that individual level characterizations that result from the level-1 model can be predicted from individual difference measures. In this particular study, the focus was on examining individual differences in

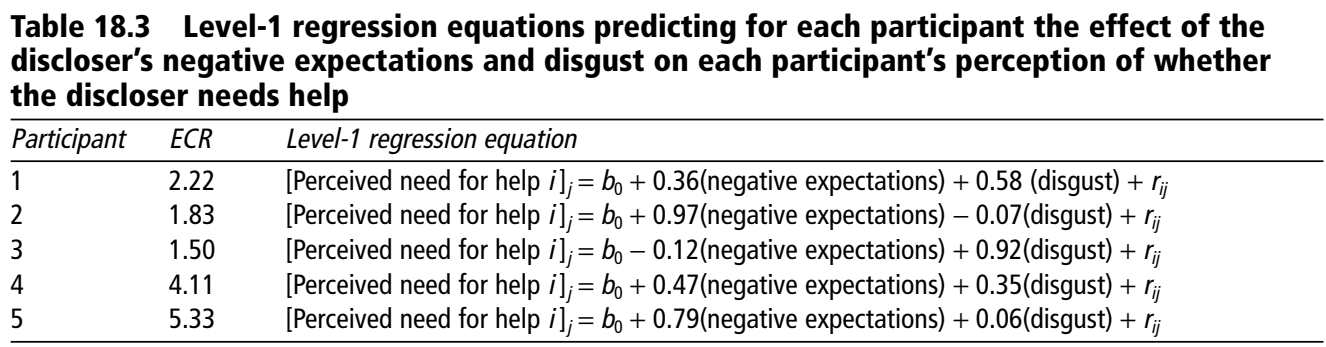

Notes: Each participant's regression equation predicts his or her perceptions of whether the discloser needs help as a function of the discloser's negative expectations and disgust. Each participant's score on the avoidance dimension of the experiences in close relationship (ECR) scale is reported in the second column (range of possible scores $=1$ to 7 ). 
attachment avoidance. The level-2 model for the slopes predicts the magnitude and direction of the association between features of disclosers' communication and perceived need for help as a function of the PSP's attachment avoidance score as measured by the Experiences in Close Relationships Questionnaire (ECR; Brennan et al., 1998). In other words, the level-2 model examines whether attachment avoidance moderates the relation between features of disclosers (i.e., whether disclosers were perceived as having negative expectations and expressing disgust) and perceived need for help. The level-2 model is as follows:

$b_{\text {neg.expectations } j}=\gamma_{\text {neg.expectations } 0}+\gamma_{\text {neg.expectations } 1}$ [PSP $j$ 's avoidance score] $+\mu_{\text {neg.expectations } j}$

$b_{\text {disgust } j}=\gamma_{\text {disgust } 0}+\gamma_{\text {disgust } 1}$ [PSP $j$ 's
avoidance score $]+\mu_{\text {disgust } j}$

The level-2 intercepts, $\gamma_{\text {neg.expectations } 0}$ and $\gamma_{\text {disgust } 0}$, can be used to examine perceived need for help in relation to negative expectations and disgust. In general, results showed that the more the discloser in a video clip displayed negative expectations, the greater the perceived need for help $\left(\gamma_{\text {neg.expectations } 0}=0.50\right.$, $t(39)=11.31, p<0.0001)$. In addition, the more the discloser in a video clip displayed disgust, the greater the perceived need for help $\left(\gamma_{\text {disgust } 0}=0.47, t(39)=10.91, p<0.0001\right)$.

Rather than assessing the moderating effect of attachment avoidance via product term interactions, multi-level modeling determines the extent to which the slopes in the level-1 model for situation features (i.e., disclosers' negative expectations and disgust, represented by $b_{\text {neg.expectations } j}$ and $b_{\text {disgust } j}$, respectively) varied as a function of participants' attachment avoidance. Attachment avoidance did not appear to moderate the relationship between negative expectations and perceived need for help $\left(\gamma_{\text {neg.expectations } 1}=\right.$ $0.06, t(39)=1.52, p=0.14)$, but it was found to be an important moderator of the relation between disgust and perceived need for help $\left(\gamma_{\text {disgust } 1}=-0.10, t(39)=-2.80, p=0.008\right)$. Participants with low attachment avoidance, compared to those with high attachment avoidance, showed a stronger relation between disclosers' expressions of disgust and their perception that help was needed.

\section{COMBINED (TOP-DOWN AND BOTTOM-UP) APPROACH TO IDENTIFYING PSYCHOLOGICAL FEATURES INFLUENCING SELF- RELEVANT EVALUATIONS}

In some cases, using a bottom-up approach in which individuals describe the features of situations that are most psychologically meaningful - may result in more features than one may wish to, or is able to, address within a study. In such cases, it may be useful to identify potentially important psychological features by combining a bottom-up approach with a top-down approach. Pre-existing theory-driven concepts are used to pare down the number of features studied. This approach is illustrated by the following research example identifying those psychological features of situations that are likely to differentially influence how people feel about themselves, that is, people's affective self-evaluation. This study further demonstrates the stability of individuals' featurebehavior profiles by using the profiles from one time point to predict affective self-evaluative responses to situations at a second time point more than one week later.

Step 1: Identify the situations in which the behavior of interest is likely to take place

As mentioned in the first two research examples, the researcher must identify where the behavior of interest is likely to take place. The behavior of interest in this study was affective self-evaluation. Therefore, the researchers aimed to find situations in which individuals would feel positively or negatively about themselves. 


\section{Step 2: Gather specific stimuli representing the situations of interest}

In contrast to the previous two illustrations, the present study used existing stimuli. Kitayama and colleagues (Kitayama et al., 1992, 1997) had participants describe situations in which their self-esteem increased or decreased. This resulted in 200 positive and 200 negative situations. Each situation described a single social episode and was usually one sentence in length (e.g., 'In an attempt to get a person's attention, I poked my nose into that person's affair and he/she became upset at me').

\section{Step 3: Identify a common set of features that could be used to capture the most psychologically important aspects of the situation of interest}

Next, a bottom-up strategy was used to identify features that might differentially predict how individuals will feel about themselves. Participants $(N=194)$ first completed a situation-self-evaluation task. This task consisted of two ten-minute blocks. In one block, negative situations from the stimulus set described in Step 2 were presented in random order one at a time on a computer screen. In the other block, positive situations were presented in random order. After reading each situation, participants rated how positively they would feel about themselves in that situation, how negatively they would feel about themselves in that situation, and how frequently they encountered each situation. A 5-point scale $(0=$ never; $4=$ frequently) was used to assess the frequency with which participants experienced each situation. Situations with mean frequency ratings less than 1.05 , indicating that they were infrequently experienced by the majority of participants, were excluded from the stimulus set of future studies (i.e., those described in Steps 4 and 5). This reduced the list to 139 negative and 168 positive situations. On average, participants rated 38 different situations $(S D=13.56)$ per block.

Next, participants completed a situation comparison task in which they were prompted to identify the features of the situations that led them to feel positively or negatively about themselves. In one of the four blocks of this task, participants saw two lists of situations, one on either side of their computer screen. For each participant, one list consisted of ten negative situations that he or she evaluated most negatively. The other list consisted of ten negative situations that he or she evaluated least negatively. ${ }^{5}$ The two lists were randomly assigned to either side of the computer screen. Participants were instructed to write a list of characteristics that the situations within each list all shared and the characteristics on which the two lists differed from one another. The remaining three blocks of the situation comparison task followed the same procedure. The only difference was that pairs of lists varied such that participants compared negative situations that they evaluated most and least positively, positive situations that they evaluated most and least positively, and positive situations that they evaluated most and least negatively. The order of these blocks was counterbalanced between participants. After the situation comparison task, all participants were asked to list any additional situation characteristics that also may have led them to feel positively or negatively about themselves. The situation comparison task and the follow-up question resulted in a list of approximately 2,700 free-response items. Using the instructions for constructing a bottom-up coding system outlined by Lampert and Ervin-Tripp (1993), the free-response data were segmented into potential coding categories (i.e., situation features). This step yielded a large and diverse set of approximately 85 potential situation features.

As a first pass, a top-down approach was applied to reduce this list of situation features to those considered to have theoretical value in the field of social psychology. Two researchers independently analyzed social psychology textbooks (Brown, 2006; Sears et al., 1991) and identified topics from the textbooks that were also reflected in the bottom-up coding categories derived from the free-response data. Those categories identified by both researchers as being represented in the free-response data and in at least one of the textbooks were selected as features to be used for this study. For example, 
one of the categories identified with this approach was 'conformity due to presence of an authority figure'. Using this procedure, 46 features were selected.

Step 4: Code the stimulus set according to a list of relevant features and derive indices reflecting presence of features

A separate sample of participants $(N=318)$ rated the extent to which each of the situations in the stimulus set contained the situation features identified from Step 3 . Situations were randomly selected without replacement from the stimulus set of 307 situations and presented one at a time on a computer screen. Participants were assigned one of the 46 situation features, and they rated the extent to which their assigned feature was present in each situation. ${ }^{6}$

Inter-rater reliabilities for each of these features were indexed by Cronbach's alpha $(\alpha)$. Eleven of the features had alphas greater than 0.80 , and they were selected for the present study (see Table 18.4 for the 11 features). The degree to which a situation reflected the presence of a feature was indexed by the mean rating of these participants.

\section{Step 5: Use a highly repeated within-subjects design to observe and record responses to stimuli}

A third set of participants $(N=37)$ completed a two-session study. In each session, participants read situations one at a time on the computer screen and rated, on two separate scales, how negatively and how positively they would feel about themselves in each situation. The scale consisted of 26 vertically aligned points anchored at the first and twenty-sixth points (e.g., 'I would not feel negative about myself' and 'I would feel extremely negative about myself', respectively.) In both sessions, participants evaluated one block of 40 negative situations randomly selected without replacement from the negative stimulus set and one block of 40 positive situations randomly selected without replacement from the positive stimulus set. Both positive and negative self-evaluations were measured in order to evaluate individual differences in within-person relations between negative and positive self-evaluation (Wang et al., 2007). For the purpose of illustration, this example will focus only on negative self-evaluation ratings in negative situations.

\section{Step 6: Analyze each participant's responses as a function of the features of the situation}

As discussed in the previous two research examples, participants' feature-behavior profiles were indexed by intraindividual slope coefficients predicting negative selfevaluation to situations from the degree to which features were present in the situations. Within each session, a standardized slope

Table 18.4 The stability of individual feature-behavior profiles for situation features between time 1 and time 2

\begin{tabular}{lcl}
\hline Situation feature & rank-order correlation & $p$ \\
\hline Shared success & 0.67 & $9.03 \times 10^{-6}$ \\
Receipt of social support & 0.44 & 0.007 \\
Academics & 0.38 & 0.02 \\
Receipt of negative feedback from others & 0.38 & 0.02 \\
Being alone & 0.37 & 0.03 \\
Poor performance due to the presence of others & 0.35 & 0.03 \\
Competition & 0.35 & 0.04 \\
Achieving success alone & 0.29 & 0.08 \\
Being misunderstood or misperceived & 0.27 & 0.1 \\
Physical activity (e.g., exercise) & 0.26 & 0.1 \\
Receipt of positive feedback & 0.13 & 0.4 \\
\hline
\end{tabular}

Notes: The stability of the profiles for each feature was indexed by Spearman's rank-order correlation coefficient predicting individuals' time 2 feature-behavior profile signatures from their time 1 signatures. Only cues with standardized Cronbach's alphas $(\alpha)$ greater than 0.80 were included in this table. 
coefficient was computed for each individual for each feature. Specifically, the level-1 model was as follows:

[Negative self-evaluation in situation $i]_{j}$ $=\beta_{0 j}+\beta_{\text {neg.feedback } j}$ [negative feedback in situation $i]+r_{i j}$
The top panel of Figure 18.3 illustrates the data for 37 participants' negative selfevaluative responses to negative situations as a function of receiving negative feedback (e.g., criticism) at time 1. Each scatterplot represents the data for one participant. The inset to the right of Figure 18.3 presents the data of participants 33,34 , and 35 .

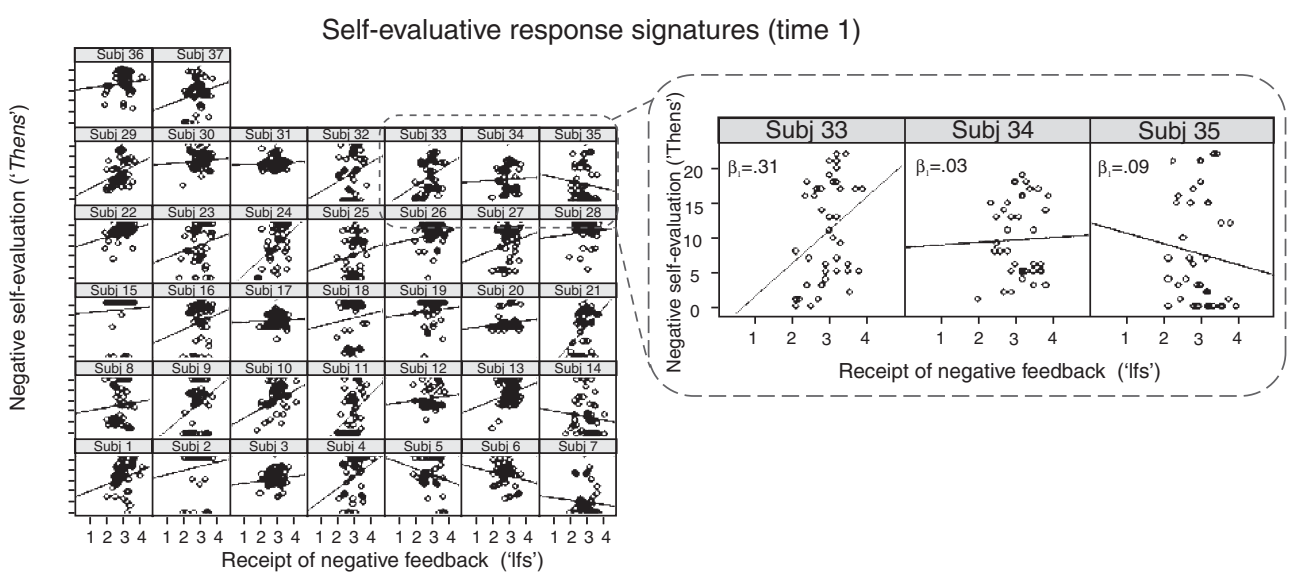

A

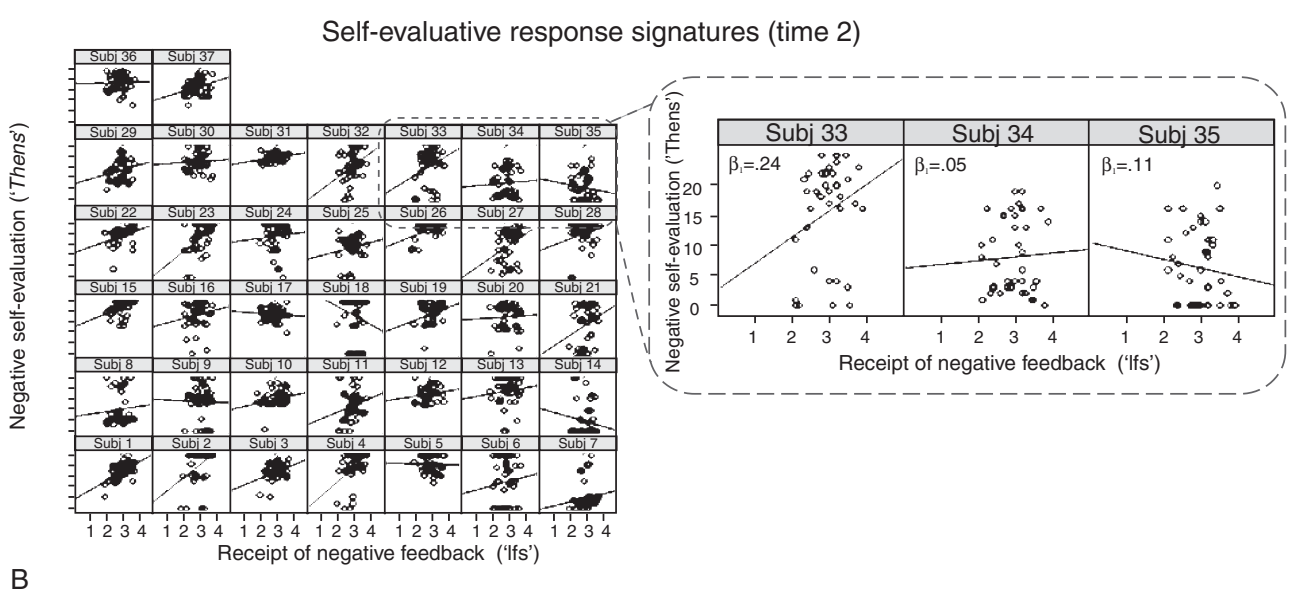

Figure 18.3 Top panel (panel A) depicts scatterplots representing the relation between the feature of the situation (i.e., receipt of negative feedback) and negative self-evaluation, for each participant at time 1 . In each graph, the $x$-axis represents the degree to which the situations involved receiving negative feedback. The $y$-axis represents participants' negative selfevaluation ratings in response to each situation. The inset to the right illustrates that, for participant 33, the greater the negative feedback present in the situation, the more he reported negative self-evaluations. The same feature had almost no effect on participant 34 and slightly an inverse effect on participant 35. Lower panel (panel B) shows scatterplots representing the relation between the same feature of the situation (i.e., receipt of negative feedback) and negative self-evaluation, for each participant at time 2. 
For participant 33, if the situation involves receiving negative feedback, then he is more likely to feel negatively about himself. This is reflected by a positive betacoefficient of 0.31 . In contrast, for participant 35 , the same feature predicted less negative self-evaluations $\left(\beta_{\text {neg.feedback }}=-0.09\right)$. For participant 34 , this feature was not predictive of negative self-evaluations $\left(\beta_{\text {neg.feedback }}=0.03\right)$.

The present study also looked at the stability, or predictive utility, of participants' feature-behavior profiles. The bottom panel of Figure 18.3 illustrates data for the same 37 participants at time 2 . The stability of the profiles for each feature was indexed by a Spearman's rank-order correlation coefficient predicting individuals' time 2 featurebehavior profile from their time 1 feature behavior profile. Table 18.4 illustrates the stability of the feature-behavior profiles for all the features. For any given feature, the more positive a correlation coefficient, the greater the stability of participants' feature-behavior profiles between sessions 1 and 2.

This research provides an illustration of a method used to identify potentially important psychological features by combining a bottom-up approach - in which individuals' self-reports of what influences their feelings about themselves were solicited - with a top-down approach in which pre-existing concepts within the field of social psychology were used to pare down the features resulting from the bottom-up approach. Variability in individuals' feature-behavior profiles suggests that they may trigger cognitive-affective processes that lead to a behavioral response, in this case, negative feeling about the self. This research also provides an example of how to identify features that yield temporally stable feature-behavior profiles. The Spearman's rank-order correlation coefficients in Table 18.4 suggest that the stability of feature-behavior profiles are strong for some features and weak for others.

\section{Strengths and limitations}

Research strategies such as the ones described in this chapter that use top-down or bottom-up approaches, or a combination of the two, allow identification of features of situations. Each approach has its own strengths and limitations and it is up to the researcher to determine the most suitable strategy for addressing a specific research question. An obvious strength of top-down approaches is that identification of features is supported by existing evidence collected from various researchers. These previous research findings can be used to identify features of situations hypothesized to affect behavior and to test specific hypotheses about the role of specific features on behavior. A weakness of top-down approaches is that they are limited to those features that have been studied in the literature. In addition, those psychological features that have been identified may be specified at varying levels of abstraction (see section on 'Feature identification and level of analyses'). Moreover, it is highly likely that not all the relevant psychological features affecting individual differences in behavior have been identified. In contrast, bottom-up approaches are based on individuals' responses, and therefore are not limited by previous research and theory. However, a limitation of bottom-up approaches is that they require that at least some participants are aware and willing to reveal the factors that affected their behaviors. Given that many processes involved in judgment, decision-making, and producing a behavioral response may be automatic and unconscious, individuals may not be aware of all the factors influencing their decisionmaking and behaviors. Social desirability processes, whether to present one's self in a positive light to others or to oneself, may also likely to affect the responses that participants provide. Finally, in some cases, a feature may be important, but may not be one that spontaneously comes to mind. 


\section{FURTHER CONSIDERATIONS}

The research projects described above illustrate approaches for identifying the psychological features of situations in different domains - situations involving preferences for and selection of potential dating partners, to those involving deciding whether an individual needs social support, to situations that may influence one's affective self-evaluations. As with any research paradigm, there are issues that each researcher needs to consider in light of his or her specific research goal. Below is a brief discussion of considerations involved in the process of feature identification.

\section{Feature identification and level of analyses}

As may be evident from the research illustrations presented so far, psychological features can be conceptualized at different levels. In the Zayas and Shoda (2007) study described earlier, for example, the level of analysis was general perceptions of personality characteristics, such as whether a potential dating partner was aggressive, impulsive, and so on. However, other researchers might have focused on more micro features such as potential partner's tone of voice or how they cope with temptation, to examine how such micro features give rise to more general perceptions of potential dating partners. A focus on more micro-level features, such as subtle nonverbal behaviors (e.g., eye gaze or vocal intonation) would address a different question: what are the features of situations that give rise to perceptions that another person is, for example, jealous or impulsive or needs help? Specifying the level of analyses for a particular project is analogous to the study of linguistics in which one goal is to understand how written words are encoded and assigned meaning. In linguistics, the first level involves orthographic analysis. Successful analysis is required for the identification of morphemes, the smallest unit of meaning, such as prefixes (un-, ad-) and suffixes (-less, -ness). These in turn may combine with other morphemes to form words. Similarly, in personality and social psychology, the process of feature identification is likely to involve stages and the researcher must decide which stage and corresponding level of analyses to focus on. Given that conceptualization and operationalization of situational features is still in the early stages, it is up to future research to derive a vocabulary for describing different levels, how the different levels correspond with one another, and the most effective demarcation of levels.

\section{Highly repeated within-subjects approach}

The techniques described in the three illustrations are useful in identifying featurebehavior profiles that differ in notable ways from those used in the original summer camp study (e.g., Shoda et al., 1994). Most important, these techniques no longer classify 'ifs' on discrete categories (e.g., peer teasing vs. teacher praise). Rather, continuous scales are used to assess the degree to which each psychological feature is present in a given situation. The use of continuous indices of situational features has also changed the statistical methods available for the analysis of the effects of situation features. Specifically, multi-level modeling allows one to simultaneously estimate the expected effect of a feature on the average individual (conceptually similar to the main effect) as well as the effect of the feature for a given individual. It does so without requiring that a situation be classified into mutually exclusive categories. Multi-level modeling also allows the analysis of the role of individual difference variables, such as attachment avoidance, without requiring that the sample be divided into discrete groups (e.g., high avoidance vs. low avoidance). 


\section{Predicting future behavior: generalizability of 'ifs'}

Ultimately, most researchers wish to say more than how a person will respond to the features of the specific stimulus set that was presented in a particular research paradigm. For example, a researcher may wish to go beyond the psychologically active features of expressions of distress in response to the specific situation of having to eat dried worms to expressions of distress elicited by a broader class of aversive situations. If one is successful in identifying psychological features that are important, identifying a particular person's feature-behavior profile in a specific research paradigm should enable us to predict what the person will do in new situations that contain the same psychological feature, even if they are nominally different situations. For example, the level-1 coefficients from the Whitsett and Shoda (2007) study, such as those that index the effect of negative expectations and disgust on perceptions of whether another person needs help, may allow one to predict each person's perception of an individual's suffering under different sources of distress, such as being unprepared for an upcoming exam.

The meaning and impact of particular psychological features often depend on the other features present in the same situation. For example, although a situation may possess fear-eliciting features that may in themselves lead to withdrawal, the situation may also possess other features, such as a highly desired goal, that simultaneously activate processing dynamics that may lead to approach, thus overriding the fear-withdrawal response. It is the set of cognitions and affects activated, rather than a single cognition that influences a person's response. This possibility can be addressed empirically by testing for interactions among features. Of course with the presence of multiple features in a given situation, the number of interactions quickly becomes unwieldy. Thus, even for bottom-up approaches, past research and theory may inform which particular interactions to examine.

\section{Building a Model of a Person}

Identifying meaningful and stable if ... then ... situation-behavior profiles, or 'behavioral signatures', is one step in building a model of a person. Ultimately, however, one needs to understand how, within a given individual, a particular situational feature (e.g., Joe's facial features that remind Mary of her father) activates cognitive (e.g., a memory of his disdain for mediocrity) and emotional (e.g., anxiety) reactions that mediate the effect of situation features on behavior. But how would one go about directly assessing such internal if ... then ... relations?

Assessing internal if ... then ... relations is a significant challenge because individuals are often not aware of the associations among their thoughts. However, there are now some promising methodologies for the assessment of automatic (i.e., not consciously controlled) associations among cognitions and affects. Recent research has shown the importance and feasibility of assessing links between specific cognitive, affective, and behavioral reactions. For example, links between situation features and cognitive and emotional reactions have repeatedly been shown to underlie the phenomenon of 'transference' (Andersen and Chen, 2002).

One approach for assessing strengths of automatic associations within each individual's CAPS network utilizes implicit measures, such as the Implicit Association Test (Greenwald et al., 1998). For example, people with secure attachment styles, compared to those with insecure styles, were shown to have stronger automatic associations between the concept of their current romantic partner and positive reactions (Zayas and Shoda, 2005). For these securely attached individuals, thoughts about their partner more strongly (compared to insecurely attached individuals) automatically 
activated positive reactions. Furthermore, the strength of such associations was found to be meaningfully related to relationship outcomes, such as greater satisfaction and emotional commitment.

Another approach builds on basic findings in research on brain activities. Specifically, a particular component of Event Related Potentials (ERP) waves in response to an event, called N400, has been shown to be magnified when participants analyze the semantic meaning of words. A typical finding using the $\mathrm{N} 400$ as an index, for example, is that targets preceded by an unrelated prime are more difficult to process (than targets preceded by a related prime), presumably because they require greater semantic analysis. Applying this finding and methodology to the social and personality domain, greater N400 reactions are observed when women encounter a negative interpersonal outcome (e.g., partner's inattention) in response to a bid for a partner's support compared to encountering the same situation in more neutral contexts (Zayas et al., under review). Moreover, according to research in adult attachment, the negative interpersonal information encountered in response to a bid for partner's support may be a psychologically salient feature of the situation, particularly for insecurely attached women (compared to securely attached women). However, given that women with insecure styles may cope with interpersonal rejection in distinctive ways - women who are considered preoccupied turn their attention towards threatening information whereas women who are highly avoidant turn their attention away from threatening information - the greatest reaction should be observed among women with a preoccupied attachment style. In other words, these women show not only a sensitivity to threatening information, but once encountered have a difficult time disengaging from it. Consistent with these ideas, women who were anxiously attached and low in attachment avoidance (also referred to as preoccupied with attachment) showed the greatest reaction to rejection words as assessed by the N400.

\section{CONCLUSIONS}

The finding that people can be characterized by stable if ... then ... situation-behavior profiles led to two related developments in the study of personality. First, there was a recognition that the field needed to reconcile the fact that people's behavior varies across situations with the core assumption of the field itself, that people possess a stable and coherent personality. This led to a reconceptualization of personality. Instead of focusing on traits, social cognitive approaches assumed that each person is characterized by a unique network of interconnected cognitions, which itself remains constant, even if the specific behaviors that arise from the network vary from one situation to another. This then suggested that that if ... then ... profiles provide clues for identifying individuality and personality coherence within individuals' crosssituational variability. This variability need not be considered a source of error to be eliminated.

But what are the 'ifs'? As a first step in constructing a cognitive social model of personality, this chapter discussed three approaches for identifying psychological significant 'ifs', or psychological features of situations. They illustrate different approaches used to identify the features of situations, and the different level of analysis involved in the conceptualization of the situation and the psychological features embedded within it.

Certainly, the task of identifying a set of psychological features that are particularly relevant for a given individual is not an easy one. But once a list of features that represent the most important features of the situation is developed, stimuli that differ in the presence of these features can the be used to examine questions such as: What features of situations activate a given individual's encodings of 
situations and generate behavior, reflecting a person's unique and stable cognitiveaffective processing system?

\section{NOTES}

1 Due to the design of the Internet dating service (IDS) procedure used to assess partner preference (Zayas and Shoda, 2007), all participants (in study 1 and 2) obtained the same average preference score. Because the average preference for all participants was zero after centering, the intercept, $b_{0 j}$, which reflects each participant's average preference score for the 16 dating partners, was not included in the level-1 model. Details regarding model specification for the HLM analysis are described in Zayas and Shoda (2007).

2 To examine the effect of the presence of specific personality traits, the HLM models were specified exactly as those described in equations (18.1), (18.2), and (18.3), except that the aggressiveness index was replaced by each personality index (e.g., impulsivity, jealousy), one at a time, as the level- 1 predictor.

3 Each participant viewed 64 of the 65 video clips randomly selected. All 65 video clips were presented an approximately equal number of times.

4 It is not necessarily the case that codes with poor inter-rater reliabilities are not useful. The low reliabilities could be due to low frequency of the feature across stimuli or simply the fact that these cues might be perceived differently by different people. In other words, they could be highly relevant for most or some people, but the effect of the feature on behavior could vary greatly from individual to individual.

5 If participants evaluated fewer than 20 negative situations, the two lists were generated by splitting the evaluated situations into the most and least negatively rated.

6 Participants who evaluated fewer than 224 $(90 \%)$ of the situations were not included in the calculation of the presence of features in situations. They did not evaluate enough situations to establish whether there was high inter-rater reliability regarding the presence of features in the situations. For the same reason of needing to establish consensus, features were also required to have been assigned to at least five participants. The reasons why only 25 of the 46 features fit the criteria described are two-fold. The main reason was because the initial computer program for this study randomly assigned participants to 1 of the 46 features. Random assignment led to an uneven distribution such that certain features were assigned to participants more frequently than others.
Once this problem was identified, block random assignment was used and participants were no longer assigned to oversampled situation features. Some features also failed to have a sufficient number of raters (i.e., five or more) because participants assigned to these features were unable to rate at least $224(90 \%)$ of the 307 situations. These criteria resulted in 25 features.

\section{REFERENCES}

Andersen, S.M. and Chen, S. (2002) 'The relational self: An interpersonal social-cognitive theory', Psychological Review, 109(4): 619-45.

Brennan, K.A., Clark, C.L. and Shaver, P.R. (1998) 'Self-report measurement of adult attachment: An integrative overview', in J.A. Simpson and W.S. Rholes (eds), Attachment Theory and Close Relationships. New York: Guilford Press, pp. 46-76.

Brown, J.D. (2006) Social Psychology. New York: McGraw-Hill.

Darley, J. M. and Latané, B. (1968) 'Bystander intervention in emergencies: Diffusion of responsibility', Journal of Personality and Social Psychology, 8(4): 377-83.

Dutton, D.G. (1994) 'Patriarchy and wife assault: The ecological fallacy', Violence and Victims, 9: 167-82.

Dutton, D.G. and Browning, J.J. (1988) 'Power struggles and intimacy anxieties as causative factors of violence in intimate relationships', in G. Russell (ed.), Violence in Intimate Relationships. New York: PMA Publishing.

Dutton, D.G., Starzomski, A. and Ryan, L. (1996) 'Antecedents of abusive personality and abusive behavior in wife assaulters', Journal of Family Violence, 11(2): 113-32.

Goldsmith, D. and Parks, M.R. (1990) 'Communicative strategies for managing the risks of seeking social support', in S. Duck and R.C. Silver (eds), Personal Relationships and Social Support. Newbury Park, CA: Sage, pp. 104-21.

Greenwald, A.G., McGhee, D.E. and Schwartz, J.K.L. (1998) 'Measuring individual differences in implicit cognition: The Implicit Association Test', Journal of Personality and Social Psychology, 74(6): 1464-80. 
Hartshorne, H. and May, M.A. (1928) Studies in the Nature of Character: Vol. 1. Studies in Deceit. New York: Macmillan.

Johnson, K.L. (2006) 'Dreading to a better end: How anticipation affects intertemporal evaluative judgments', Unpublished manuscript, New York University.

Kasian, M. and Painter, S.L. (1992) 'Frequency and severity of psychological abuse in a dating population', Journal of Interpersonal Violence, 7(3): 350-64.

Kelley, H.H., Holmes, J.G., Kerr, N., Reis, H., Rusbult, C.E. and Van Lange, P.A. (2003) An Atlas of Interpersonal Situations. Cambridge: Cambridge University Press.

Kitayama, S., Markus, H.R., Matsumoto, H. and Norasakkunkit, V. (1997) 'Individual and collective processes in the construction of the self: Self-enhancement in the United States and self-criticism in Japan', Journal of Personality and Social Psychology, 72(6): 1245-67.

Lampert, M.D. and Ervin-Tripp, S.M. (1993) 'Structured coding for the study of language and social interaction', in J.A. Edwards and M.D. Lampert (eds), Talking Data: Transcription and Coding in Discourse Research. Hillsdale, NJ: Erlbaum, pp. 169-206.

Miller, S.M. (1987) 'Monitoring and blunting: Validation of a questionnaire to assess styles of information seeking under threat', Journal of Personality and Social Psychology, 52(2): 345-53.

Mischel, W. and Shoda, Y. (1995) 'A cognitiveaffective system theory of personality: Reconceptualizing situations, dispositions, dynamics, and invariance in personality structure', Psychological Review, 102(2): 246-68.

Murphy, C.M., Meyer, S.L. and O'Leary, K.D. (1994) 'Dependency characteristics of partner assaultive men', Journal of Abnormal Psychology, 103(4): 729-35.

Newcomb, T.M. (1929) 'The consistency of certain extrovert-introvert behavior patterns in 51 problem boys', Contributions to Education, No. 382, Columbia University, New York.

Sears, D.O., Peplau, L.A. and Taylor, S.E. (1991) Social Psychology. New Jersey: Prentice Hall.

Shoda, Y. (1990) 'Conditional analyses of personality coherence and dispositions', $\mathrm{PhD}$ dissertation, Columbia University.
Shoda, Y. (2003) 'Individual differences in social psychology: Understanding situations to understand people, understanding people to understand situations', in C. Sansone, C.C. Morf and Panter, A.T. (eds), The Sage Handbook of Methods in Social Psychology. Thousand Oaks, CA: Sage, pp. 117-41.

Shoda, Y. and Mischel, W. (1998) 'Personality as a stable cognitive-affective activation network: Characteristic patterns of behavior variation emerge from a stable personality structure', in S.J. Read and L.C. Miller (eds), Connectionist and PDP Models of Social Reasoning and Social Behavior. New Jersey: Lawrence Erlbaum, pp. 175-208.

Shoda, Y., Mischel, W. and Wright, J.C. (1989) 'Intuitive interactionism in person perception: Effects of situation-behavior relations on dispositional judgments', Journal of Personality and Social Psychology, 56(1): 41-53.

Shoda, Y., Mischel, W. and Wright, J.C. (1993a) 'The role of situational demands and cognitive competencies in behavior organization and personality coherence', Journal of Personality and Social Psychology, 65(5): 1023-35.

Shoda, Y., Mischel, W. and Wright, J.C. (1993b) 'Links between personality judgments and contextualized behavior patterns: Situationbehavior profiles of personality prototypes', Social Cognition, 4(11): 399-429.

Shoda, Y., Mischel, W. and Wright, J.C. (1994) 'Intra-individual stability in the organization and patterning of behavior: Incorporating psychological situations into the idiographic analysis of personality', Journal of Personality and Social Psychology, 67(4): 674-87. (Article also reprinted as a chapter in Cooper, C.L. and Pervin, L.A. (1998) Personality: Critical Concepts in Psychology. New York/London: Routledge.)

Walker, L.E. (1979) The Battered Woman. New York: Harper \& Row.

Walters, B. (1992) [Interview of David Letterman, January 29, 1992].

Wang, J., Lee, J.J., Shoda, Y. and Leu, J. (2007) 'Culture and self evaluation: An idiographic approach', Poster presented at the Annual Meeting of the Society for Personality and Social Psychology, Memphis.

Whitsett, D.D. and Shoda, Y. (2007) 'Providing emotional support to individuals in distress: Women's utilization of nonverbal cues', 
Poster presented at the Annual Meeting of the Society for Personality and Social Psychology, Memphis.

Wright, J.C. and Mischel, W. (1987) 'A conditional approach to dispositional constructs: The local predictability of social behavior', Journal of Personality and Social Psychology, 53(6): 1159-77.

Wright, J.C. and Mischel, W. (1988) 'Conditional hedges and the intuitive psychology of traits', Journal of Personality and Social Psychology, 55(3): 454-69.

Zayas, V. and Shoda, Y. (2005) 'Do automatic reactions elicited by thoughts of romantic partner, mother, and self relate to adult romantic attachment?', Personality and Social Psychology Bulletin, 31(8): 1011-25.

Zayas, V. and Shoda, Y. (2007) 'Predicting preferences for dating partners from past experiences of psychological abuse: Identifying the "psychological ingredients" of situations', Personality and Social Psychology Bulletin, 33(1): 123-38.

Zayas, V., Shoda, Y. and Ayduk, O.N. (2002) 'Personality in context: An interpersonal systems perspective', Journal of Personality, 70(6): 851-900.

Zayas, V., Shoda, Y., Osterhout, L., Takahashi, M.M. and Mischel, W. (under review) 'Neural responses to partner rejection cues'. 